\title{
Comparative Study of Three Different Brands of Doxycycline Capsules Available in Karachi
}

\author{
Safila Naveed*, Nimra Waheed \\ Faculty of Pharmacy, Jinnah University for Women, Karachi, Pakistan \\ Email: safila117@yahoo.com
}

Received 4 March 2014; revised 17 April 2014; accepted 25 April 2014

Copyright (C) 2014 by authors and OALib.

This work is licensed under the Creative Commons Attribution International License (CC BY). http://creativecommons.org/licenses/by/4.0/

(c) (i) Open Access

\begin{abstract}
Doxycycline (DOX) is lipophilic and synthetic derivative of tetracycline. DOX is a bacteriostatic agent that is active against gram-positive and gram-negative aerobic and anaerobic bacteria, Mycoplasmas, Chlamydiae, Rickettsiae, and some Protozoa. It inhibits the protein synthesis by restricting the binding of RNA to $30 \mathrm{~S}$ ribosomal subunit. It is used for inflammatory conditions; periodontitis and acute coronary syndromes, variety of cancers, pulmonary fibrosis, emphysema, asthma, acute lung injury and for prophylaxis of malaria. The aim of this study is to evaluate the pharmaceutical equivalence of the three different brands of doxycycline capsules available in Karachi, Pakistan. For this purpose three different brands of doxycycline capsules $(100 \mathrm{mg})$ were randomly selected from the local market using probability tools and evaluated for quality control parameters which are weight variation, disintegration and dissolution tests specified by BP/USP (British and United state Pharmacopoeia). Weight variation values of all brands comply with USP limits. Disintegration time for all brands was within 15 minutes also complying with the USP specification. All brands exhibited more than $80 \%$ drug release within 20 minutes. The present outcomes suggest that all the three brands of doxycycline capsule available in Karachi meet the USP specification for quality control analysis.
\end{abstract}

\section{Keywords}

Doxycycline, Dissolution, Disintegration, Weight Variation, Available Brands

\section{Introduction}

Doxycycline is a liphophilic and semi synthetic derivative of natural tetracyclines which is produced by Strep-

"Corresponding author. 
tomyces sp. Bacteria [1]. It is a bacterioststic agent having a broad spectrum activity against Gram-positive and Gram-negative anaerobic and aerobic bacteria, Mycoplasmas, Chlamydiae, Rickettsiae, and some Protozoa [2]. Doxycycline was firstly invented and clinically developed by Pfizer Inc., New York in the early 1960s and marketed under the trade name Vibramycin [3] [4]. Mechanism of action of DOX is that it acts by restricting the binding of aminoacyl t-RNA to 30S ribosomes which helps in the inhibition of protein synthesis. Tetracyclines (e.g. DOX) are believed to hinder the mitochondrial protein synthesis that leads to the innovation of other effects, independent of their antimicrobial actions [5] [6]. Tetracycline has improved lipophilicity as compared to older tetracyclines, for example oxytetracycline and tetracycline [7]. Doxycycline demonstrates immune-modulating activities that have been used in the treatment of numerous inflammatory conditions mediated by matrix metalloproteinase (MMP-9) and recover inflammatory biomarkers in patients with abdominal aortic aneurysms. It helps to prevent periodontitis and acute coronary syndromes. In recent times, the advancement in the study of tetracycline has developed due to their ability to inhibit matrix metalloproteinase (MMPs) in a variety of cancers such as breast, colorectal, osteosarcoma, melanoma, leukemia and prostate cancers [8]. Additionally, doxycycline has shown favorable effects in trial models of pulmonary fibrosis, emphysema, asthma and acute lung injury [9]. It also has many additional properties such as they provide anti-resorption result and prevent tissue breakdown by the inhibition of clastic cells and the inhibition of mammalian collagenases respectively. DOX also blocks excess of tissue collagenases which is present in periodontitis (an inflammatory disease), consequently leading to enhanced formation of bone and collagen [10]. DOX is approved by only United State Food and Drug Administration (FDA) to be indication in short-term travelers for malaria as prophylaxis of Plasmodium falciparum where the strains are resistant to pyrimethamine-sulfadoxine and/or chloroquine [11]. Second-generation, doxycycline is rapidly and well absorbed (95\%) after oral administration than first-generation due to their increase lipid solubility, being measurable in blood in less than 15 minutes [12]. It is available in the various pharmaceutical dosage forms and strengths such as suspension $(25 \mathrm{mg} / 5 \mathrm{ml}$ and $50 \mathrm{mg} / 5 \mathrm{ml})$, immediate (20 and $100 \mathrm{mg}$ ) and delayed release tablets (75, 100 and $150 \mathrm{mg})$, immediate (50, 75 and $100 \mathrm{mg}$ ) and delayed release capsules (40, 75 and $100 \mathrm{mg}$ ) [13]. Doxycycline is (4S,4aR,5S,5aR,6R,12aS)-4-(Dimethylamino)-3,5,10,12,12a-pentahydroxy6-methyl-1,11-dioxo-1,4,4a,5,5a,6,11,12a-octahydro-2-tetracenecarboxamide having molecular formula: $\mathrm{C}_{22} \mathrm{H}_{26} \mathrm{~N}_{2} \mathrm{O}_{9}$ with molecular mass: 444.434601 and the molecular structure in Figure 1 [14].

\section{Methodology}

We have purchased different brands of doxycycline hyclate capsules (USP) of $100 \mathrm{mg}$ from the local market i.e. VIBRAMYCIN(VIB), DOXYN(DOXN) and DOXYCYCLINE(DOXC). Different physicochemical testing were performed to compare multinational brand with the local brands.

\subsection{Weight Variation Test}

Weight Variation (in process test) ensures that content of each dosage units is uniform during compression. For this 10 capsules of each brand was weighed on Electronic Balance FX-400 and calculated that weight of each capsule must be within BP/USP limits i.e. for capsules containing less than 300 mg NMT two capsules out of the sample may be outside $\pm 10 \%$ of the average and all must be within $20 \%$.

\subsection{Disintegration Test}

for this test we use a disintegration apparatus (Curro model no DS-0702) and Place one capsule in each of the six tubes of the basket and add a disc (if specified) Operate the apparatus by maintaining its temperature at $35^{\circ} \mathrm{C}$ - $39^{\circ} \mathrm{C}$ using water or another liquid (unless specified )as the immersion fluid. Finally at the specified time, pick<smiles>C[C@H]1c2cccc(O)c2C(=O)C2=C(O)[C@]3(C(=O)C(C(N)=O)=C(O)[C@H](N(C)C)[C@H]3[C@H]2O)[C@@H]1C</smiles>

Figure 1. Structure of doxycycline. 
up the basket from the fluid and examine whether all of the capsules have disintegrated completely. If one or two capsules fail to disintegrate, the test is repeated on 12 extra capsules. If NLT 16 of the 18 capsules tested are disintegrated the requirements is met. Follow the same procedure for each brand. According to USP, capsule should disintegrate in NMT 30 minutes [15].

\subsection{Dissolution Test}

We perform this test on GDT-7L of Galvano Scientific dissolution apparatus. For this we Place the 900ml of water in the vessel, assemble the equipment and place it in the water-bath maintained at temperature $37^{\circ} \mathrm{C} \pm$ $0.5^{\circ} \mathrm{C}$. At the beginning of each test, put one capsule of each brand in a dry basket. Lower the basket into position before rotation. Instantaneously start rotation of the basket at $50 \mathrm{RPM}$. Withdraw a sample of $10 \mathrm{ml}$ at 15 , 30, 45 and 60 min respectively from each vessel. The sample must be taken from a zone midway between the surface of the dissolution medium and the top of the rotating basket, not less than $10 \mathrm{~mm}$ below the surface and at least $10 \mathrm{~mm}$ from the vessel wall. Determine the quantity of doxycycline dissolved as specified in USP. It is a best tool to evaluate the bioavailability of drug in vivo.

\section{Results}

The physicochemical parameters of different brands of doxycycline capsules (VIB 01, DOXN 02 and DOXC 03) were analyzed. The results of average weight of 10 capsules of VIB-01, DOXN-02, DOXC03 is $366.6 \mathrm{mg}, 283.5$ mg, 207.9 mg and their upper \& lower limits are 382.67 - 349.851, 307.51 - 259.489, 223.8 - 191.99 respectively which is show in Table 2 and Table 3. Disintegration Test is carried out on VIB 01, DOXN 02, DOXC 03 and they disintegrate in 1.35, 1.15 and 2.15 minutes respectively shown in Table 5. Dissolution test demonstrate the result as VIB01 is 100.00\%, DOXN 02 is $151.06 \%$ and DOXC 03 is 109.05\% shown in Table 6 and Table 7.

\section{Discussion}

The purpose of this research work is to evaluate and compare the quality standards of three brands of doxycycline capsules (VIB, DOXN and DOXC) commercially available in Karachi, Pakistan specification are given in Table 1. For comparatively study, physicochemical testing such as weight variation, in-vitro dissolution and disintegration of doxycycline capsules $(100 \mathrm{mg}$ ) were performed and evaluated. Dissolution, disintegration and Uniformity of weight (weight variation) are compendia standards to assess the quality of capsules.

\section{Weight Variation}

The weight variation values of VIB, DOXN and DOXC are given in Table 2, Figure 2, which shows that VIB 01 has the highest value of mean weight among all the three brands. According to USP the requirements of weight variation are met when out of 20 capsules of each brand the weight of not more than 2 capsules differs from the average weight by more than $10 \%$ (Table 4). Difference in weight between these 3 brands (VIB, DOXN and DOXC) of doxycycline capsules is due to the non-uniform amount of an API. Uniformity of weight serves as an indicator to amount of the active pharmaceutical ingredient i.e. doxycycline enclosed in the formulation as well as good manufacturing practices i.e. GMP.

\section{Disintegration}

VIB and DOXN have less disintegration time as compared to DOXC which is show in Table 5, Figure 3.

Table 1. Specification of drug with code No. and batch No.

\begin{tabular}{cccc}
\hline No. & Product name & Serial No. & Code No. \\
\hline 1 & vibramycin & VIB & 000456 \\
2 & doxyn & DOXN & 005999 \\
3 & doxycycline & DOXC & 031290 \\
\hline
\end{tabular}


Table 2. Statistical weight variation table.

\begin{tabular}{rccccc} 
Serial No. & Batch No. Average Weight $(\mathbf{m g})$ & STDEV $(\mathbf{m g})$ & Upper Limit $(\mathbf{U C L})(\mathbf{X}+3 \mathbf{3})(\mathbf{m g})$ & Lower Limit $(\mathbf{L C L})(\mathbf{X}-\mathbf{3 S})(\mathbf{m g})$ \\
\hline VIB 01 & 1458003 & 366.6 & 5.3583 & 382.67 & 349.851 \\
DOXN 02 & 13005 & 283.5 & 8.0035 & 307.51 & 259.489 \\
DOXC 03 & 82 & 207.9 & 5.301 & 223.8 & 191.99
\end{tabular}

Table 3. Calculation for weight variation test.

\begin{tabular}{|c|c|c|c|c|c|c|c|c|c|c|}
\hline VIB & CAP1 & CAP2 & CAP3 & CAP4 & CAP5 & CAP6 & CAP7 & CAP8 & CAP9 & CAP10 \\
\hline WEIGHT & 374 & 360 & 364 & 361 & 375 & 367 & 369 & 365 & 370 & 361 \\
\hline MEAN & 366.6 & 366.6 & 366.6 & 366.6 & 366.6 & 366.6 & 366.6 & 366.6 & 366.6 & 366.6 \\
\hline SD & 5.3583 & 5.3583 & 5.3583 & 5.3583 & 5.3583 & 5.3583 & 5.3583 & 5.3583 & 5.3583 & 5.3583 \\
\hline UCL & 382.67 & 382.67 & 382.67 & 382.67 & 382.67 & 382.67 & 382.67 & 382.67 & 382.67 & 382.67 \\
\hline LCL & 349.851 & 349.85 & 349.851 & 349.851 & 349.851 & 349.851 & 349.851 & 349.851 & 349.851 & 349.85 \\
\hline COMMENTS & $\mathrm{OK}$ & OK & $\mathrm{OK}$ & OK & OK & $\mathrm{OK}$ & OK & OK & OK & OK \\
\hline DOXN & CAP1 & CAP2 & CAP3 & CAP4 & CAP5 & CAP6 & CAP7 & CAP8 & CAP9 & CAP10 \\
\hline WEIGHT & 287 & 270 & 273 & 277 & 289 & 286 & 285 & 295 & 291 & 282 \\
\hline MEAN & 283.5 & 283.5 & 283.5 & 283.5 & 283.5 & 283.5 & 283.5 & 283.5 & 283.5 & 283.5 \\
\hline SD & 8.00347 & 8.0035 & 8.00347 & 8.00347 & 8.00347 & 8.00347 & 8.00347 & 8.00347 & 8.00347 & 8.0035 \\
\hline UCL & 307.51 & 307.51 & 307.51 & 307.51 & 307.51 & 307.51 & 307.51 & 307.51 & 307.51 & 307.51 \\
\hline LCL & 259.489 & 259.49 & 259.489 & 259.489 & 259.489 & 259.489 & 259.489 & 259.489 & 259.489 & 259.49 \\
\hline COMMENTS & $\mathrm{OK}$ & OK & $\mathrm{OK}$ & $\mathrm{OK}$ & $\mathrm{OK}$ & OK & OK & OK & OK & OK \\
\hline DOXC & CAP1 & CAP2 & CAP3 & CAP4 & CAP5 & CAP6 & CAP7 & CAP8 & CAP9 & CAP10 \\
\hline WEIGHT & 202 & 202 & 205 & 209 & 214 & 207 & 208 & 218 & 203 & 211 \\
\hline MEAN & 207.9 & 207.9 & 207.9 & 207.9 & 207.9 & 207.9 & 207.9 & 207.9 & 207.9 & 207.9 \\
\hline SD & 5.301 & 5.301 & 5.301 & 5.301 & 5.301 & 5.301 & 5.301 & 5.301 & 5.301 & 5.301 \\
\hline UCL & 223.8 & 223.8 & 223.8 & 223.8 & 223.8 & 223.8 & 223.8 & 223.8 & 223.8 & 223.8 \\
\hline LCL & 191.99 & 191.99 & 191.99 & 191.99 & 191.99 & 191.99 & 191.99 & 191.99 & 191.99 & 191.99 \\
\hline COMMENTS & OK & OK & OK & OK & OK & OK & OK & OK & OK & OK \\
\hline
\end{tabular}

Table 4. Weight variation Test.

\begin{tabular}{|c|c|c|c|c|}
\hline Serial No. & Batch No. & Result (mg) & USP Specification & Deviation from USP \\
\hline VIB 01 & 1458003 & 366.6 & $\pm 10 \%$ & Pass \\
\hline DOXN 02 & 13005 & 283.5 & $\pm 10 \%$ & Pass \\
\hline DOXC 03 & 82 & 207.9 & $\pm 10 \%$ & Pass \\
\hline
\end{tabular}


Table 5. Disintegration test.

\begin{tabular}{ccccc}
\hline Serial No. & Batch No. & Disintegration Time (min) & Limits & Deviation from USP \\
\hline VIB 01 & 1458003 & 1.35 & NMT 15 Min & PASS \\
DOXN 02 & 13005 & 1.15 & NMT 15 Min & PASS \\
DOXC 03 & 82 & 2.15 & NMT 15 Min & PASS \\
\hline
\end{tabular}

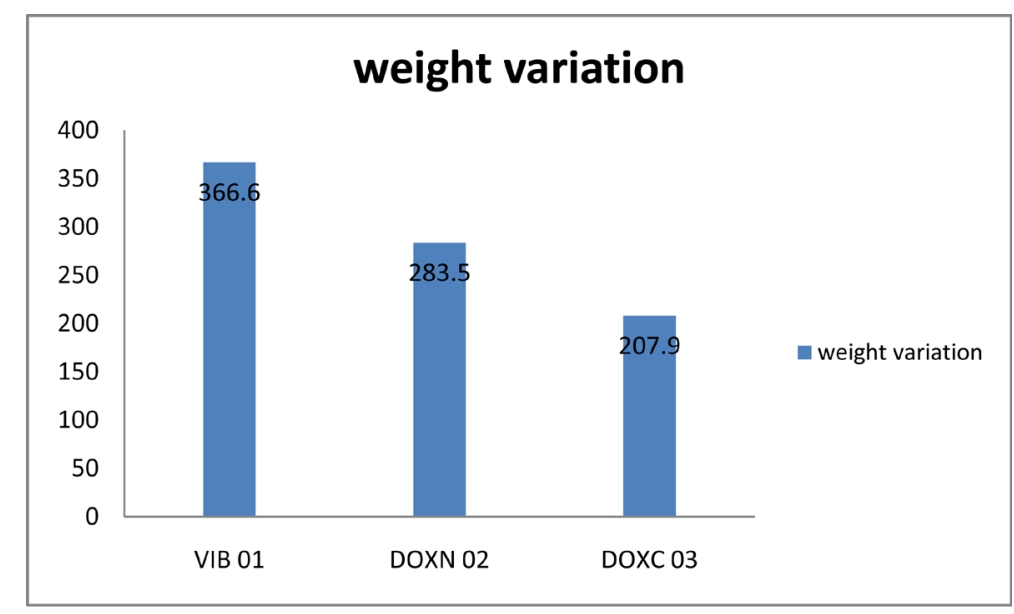

Figure 2. Weight variation of different brands of doxycycline.

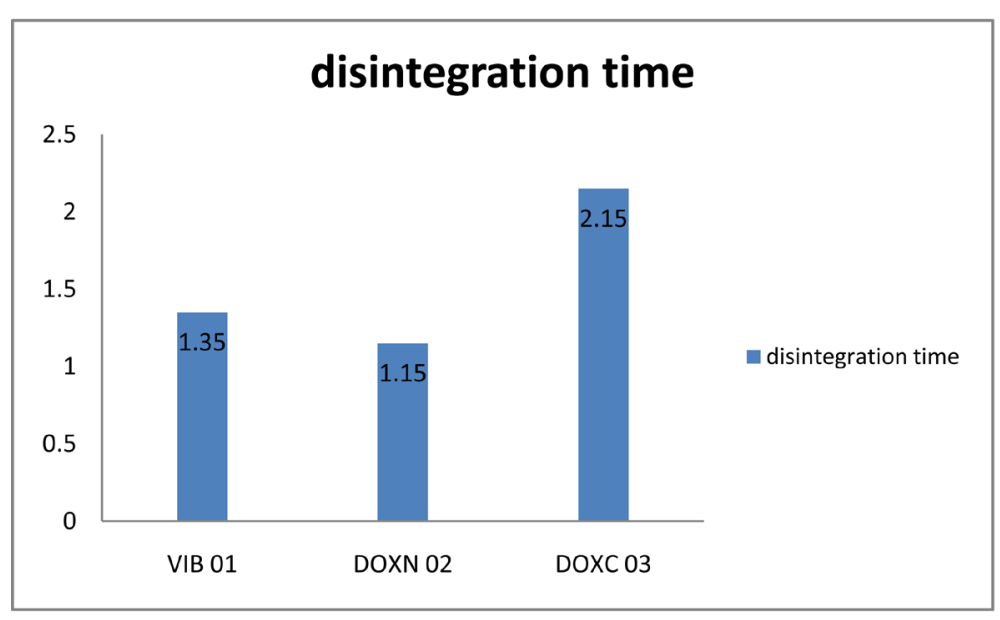

Figure 3. Disintegration time of doxycycline capsules of 3 different brands.

According to USP specification; capsules should disintegrate in NMT 30 minutes. DOXN and VIB took less time to disintegrate i.e. 1.15 and 1.35 min whereas DOXC took more time i.e. 2.15 min as compared to other two brands. The disintegration time for all the 3 brands of doxycycline capsules met with USP specification.

\section{Dissolution}

The absorbance and percentage of all brands of doxycycline (VIB, DOXN and DOXC) dissolved in 30 min are shown in Table 6 and Table 7, Figure 4. As per USP official limits for doxycycline capsules, dissolved amount of doxycycline should NLT 80\% (Q) of the labeled amount in $60 \mathrm{~min}$ and all the brands are under the specified limit. 
Table 6. Absorbance at different time interval.

\begin{tabular}{cccccc}
\hline & & \multicolumn{4}{c}{ Absorbance of Drug } \\
Serial No. & Batch No. & $\mathbf{1 5} \mathbf{~ m i n}$ & $\mathbf{3 0} \mathbf{~}$ in & $\mathbf{4 5} \mathbf{~ m i n}$ & $\mathbf{6 0} \mathbf{~ m i n}$ \\
\cline { 3 - 5 } & 1458003 & 1.120 & 1.126 & 1.125 & 1.056 \\
VIB 01 & 13005 & 1.667 & 1.701 & 1.640 & 1.603 \\
DOXN 02 & 82 & 1.409 & 1.228 & 1.083 & 1.000 \\
\hline
\end{tabular}

Table 7. Dissolution test.

\begin{tabular}{|c|c|c|c|c|}
\hline Serial No. & Batch No. & Dissolution at $30 \mathrm{~min}$ & USP Spec & Deviation from USP \\
\hline VIB 01 & 1458003 & $100.00 \%$ & & pass \\
\hline DOXN 02 & 13005 & $151.06 \%$ & $\begin{array}{l}\text { Not less than } 80 \%(\mathrm{Q}) \\
\text { of the labeled amount } \\
\text { dissolved in } 30 \mathrm{~min}\end{array}$ & pass \\
\hline DOXC 03 & 82 & $109.05 \%$ & & pass \\
\hline
\end{tabular}

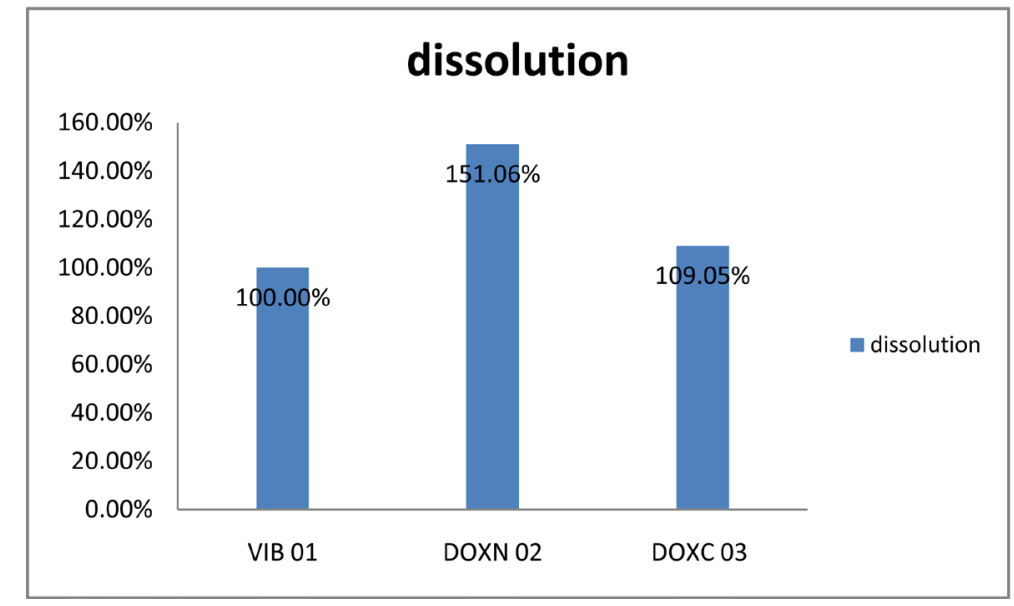

Figure 4. Dissolution of 3 brands of doxycycline capsules in 30 minutes.

\section{Conclusion}

It is concluded that the results of all the tests (weight variation, disintegration and dissolution) of selected brands of doxycycline capsules (100 mg) exhibit some differences, but these variations are in specified limits.

\section{References}

[1] McEvoy, G. (editor) (2008) AHFS Drug Information. American Society of Health-System Pharmacists, Inc., Bethesda. (Tetracyclines)

[2] Abu-Basha, E.A., Idkaidek, N.M. and Hantash, T.M. (2006) Pharmacokinetics and Bioavailability of Doxycycline in Ostriches (Struthio camelus) at Two Different Dose Rates. Journal of Veterinary Science, 7, 327-332. http://dx.doi.org/10.4142/jvs.2006.7.4.327

[3] Rieckmann, K.H., McNamara, J.V., Willerson, D., Kass, L., Frischer, J. and Carson, P.E. (1971) Effects of Tetracycline against Chloroquineresistant and Cloroquine-Sensitive Plasmodium falcuparum. The American Journal of Tropical Medicine and Hygiene, 20, 811-815.

[4] Clyde, D.F., DuPont, H.L. and Hornick, R.B. (1971) Antimalarial Effects of Tetracyclines in Man. The Journal of Tropical Medicine and Hygiene, 74, 238-242.

[5] Clark Jr., J.M. and Chang, A.Y. (1965) Inhibitors of the Transfer of Amino Acids from Aminoacyl Soluble Ribonucleic Acid to Proteins. The Journal of Biological Chemistry, 240, 4734-4739. 
[6] Saikali, Z. and Singh, G. (2003) Doxycycline and Other Tetracyclines in the Treatment of Bone Metastasis. Anticancer Drugs, 14, 773-778. http://dx.doi.org/10.1097/00001813-200311000-00001

[7] Bryskier, A. (2005) Tetracyclines. In: Bryskier, A., Ed., Antimicrobial Agents. Antibacterials and Antifungals, ASM Press, Washington DC, 642-651.

[8] Sagar, J., Sales, K., Dijk, S. and Taanman, J. (2009) Alexander Seifalian, and Mark Winslet Does Doxycycline work in Synergy with Cisplatin and Oxaliplatin in Colorectal Cancer? World Journal of Surgical Oncology, 7, 2. http://dx.doi.org/10.1186/1477-7819-7-2

[9] Beringer, P.M., Owens, H., Nguyen, A., Benitez, D., Rao, A. and D’Argenio, D.Z. (2012) Pharmacokinetics of Doxycycline in Adults with Cystic Fibrosis. Antimicrobial Agents and Chemotherapy, 56, 70-74. http://dx.doi.org/10.1128/AAC.05710-11

[10] Mohammadi, Z. and Abbott, P.V. (2009) On the Local Applications of Antibiotics and Antibiotic-Based Agents in Endodontics and Dental Traumatology. International Endodontic Journal, 42, 555-567. http://dx.doi.org/10.1111/j.1365-2591.2009.01564.x

[11] Tan, K.R., Magill, A.J., Parise, M.E. and Arguin, P.M. (2011) Doxycycline for Malaria Chemoprophylaxis and Treatment: Report from the CDC Expert Meeting on Malaria Chemoprophylaxis. The American Journal of Tropical Medicine and Hygiene, 84, 517-531. http://dx.doi.org/10.4269/ajtmh.2011.10-0285

[12] Valentín, S., Morales, A., Sánchez, J.L. and Rivera, A. (2009) Safety and Efficacy of Doxycycline in the Treatment of Rosacea. Clinical, Cosmetic and Investigational Dermatology, 2, 129-140.

[13] FDA.gov (homepage on the Internet) Approved Drug Products with Therapeutic Equivalence Evaluations (Orange Book) (updated 2009 Jan 23; cited 2009 Feb 26). http://www.fda.gov/cder/orange/default.htm

[14] http://www.chemspider.com/Chemical-Structure.10482106.html

[15] Jones, B.E. (2004) Capsule Standards, Chapter 13: Pharmaceutical Capsules. 2nd Edition, Pharmaceutical Press RPS Publishing, London, 241-250. 